\title{
THOMAS A. SEBEOK
}

\section{Zoosemiotics: \\ At the Intersection of Nature and Culture}




\section{(C) Copyright reserved}

No part of this text may be translated or reproduced in any form, by print, photoprint, microfilm or any other means without written permission from the author.

The text of this article is reprinted from

Thomas A. Sebeok (ed.), The Tell-Tale Sign: A Survey of Semiotics

(Lisse, The Peter de Ridder Press, 1975), pp. 85-95

Printed in Belgium by N.I.C.I., Ghent 